\title{
On the question of reducing deformability of subsiding soils in construction of multi-storey apartment buildings
}

\author{
Vladimir Perov ${ }^{1, *}$, and Sergei Perov ${ }^{1}$ \\ ${ }^{1}$ LLC "Fundamentstroiproekt", Orenburg, Russia
}

\begin{abstract}
The article deals with the method of reducing the compressibility of the subsidence soil under the bottom of a slab foundation of a multi-storey apartment building by reinforcing the soil with rigid elements, which are concrete piles in rolled wells. This method is effective because it eliminates the subsidence properties of the soil and significantly increases the deformation modulus, which causes a decrease in the amount of precipitation of the foundations of the designed object. An example of the use of this method for a multi-storey apartment building and the results of field plate load tests of artificially improved soil are given.
\end{abstract}

\section{Introduction}

Engineering and geological surveys on construction sites in the Northern residential area of Orenburg revealed the presence of subsidence soils at the top of the logs with thickness from 2.0 to $9.0 \mathrm{~m}$ in depth. This revealing demands from designers of multi-storey apartment buildings (from 12 to 25 storey height), based on a monolithic foundation slab with the pressure on the soil from 0.25 to $0.40 \mathrm{MPa}$, the solution of the following task:

- reducing of settlement values or differential settlements for one section as well as for adjacent sections leading to a building tilt.

To reduce the values of settlements and differential settlements the following competitive options may be used:

- driving or bored piles with full or partial cutting of the slumping stratum;

- slab-pile foundation;

- layer-by-layer compaction of subsiding soil;

- chemical fixation of subsiding soil (silicification, alkalinisation);

- compaction with ground piles in punched wells;

- reinforcement of subsiding soil with rigid elements, such as bored piles or piles in rolled wells filling by compacted soil, soil-cement, crushed stone, concrete or augercast piles.

\section{Description of the object and engineering and geological conditions of the site}

*Corresponding author: fstpr@mail.ru 
This article gives the example of the use of foundation strengthen with rigid elements - piles in rolled wells - during the underpinning of the base of a 17-storey apartment building in Orenburg. The panel apartment building consists of 5 sections with the foundations in the form of a monolithic reinforced concrete plate with the sizes of $14 \times 28$ meters. The depth of the bottom of the base plate is $3.0 \mathrm{~m}$. Engineering and geological conditions of the site, according to the research conducted by JSC "OrenburgTISIZ" in 2016, are represented by the following superposition:

EGE-1 - the subsiding loam of brown color, from solid to semi-solid state, macroporous, carbonatized (rapidly boils up in $\mathrm{HCl} 10 \%$ ) with interlayers of the sand with thickness of up to $0.5 \mathrm{~cm}$, nonsaline, slightly swollen, non-swelling.

The top of the loam is opened at a depth of $0.2 \div 0.3 \mathrm{~m}$ from the ground surface. The bottom is opened at a depth of $7.0 \div 8.0 \mathrm{~m}$; the thickness varies from 6.7 to $7.8 \mathrm{~m}$.

The characteristic values of physical and mechanical characteristics are as follows:

- soil density - $1.75 \mathrm{~g} / \mathrm{cm}^{3}$;

- density of solids $-2.70 \mathrm{~g} / \mathrm{cm}^{3}$;

- natural moisture - 0.18 u.f.;

- dry soil density $-1.49 \mathrm{~g} / \mathrm{cm}^{3}$;

- porosity index - 0.83 u.f.;

- water saturation coefficient - 0.59 u.f.;

- humidity at the limit of plasticity -0.21 ;

- liquid limit - 0.32;

- plasticity index -0.11 ;

- index of liquidity $<0$;

- deformation modulus in natural state - $21 \mathrm{MPa}$;

- deformation modulus at water saturation - $15 \mathrm{MPa}$;

- angle of internal friction- $23^{\circ}$;

- specific cohesion - $25 \mathrm{kPa}$.

The site belongs to the first type of subsidence that appears under the influence of an external load. The subsidence under the influence of sole weight isn't revealed. According to the value of the relative strain of subsidence under the loads of $0.40-0.50 \mathrm{MPa}(0.014-0.022)$, the soil is of low subsidence. EGE-2 - the non-subsiding loam of brown color, from solid to semi-solid state, with individual macropores, carbonatized, with sand interlayers with the thickness of up to $0.5 \mathrm{~cm}$, with land waste and sandstone up to $5 \%$ at the bottom, non-saline, non-swelling. The top of the non-subsiding loam is opened at a depth of $7.0 \div 8.0 \mathrm{~m}$ from the ground surface. The sole is opened at a depth of $10.6 \div 15.5 \mathrm{~m}$. The thickness varies from 3.3 to $8.4 \mathrm{~m}$. The characteristic values of physical and mechanical characteristics of EGE-2 are as follows:

- soil density $-1.91 \mathrm{~g} / \mathrm{cm}^{3}$

- natural moisture $-0.19 \%$;

- dry soil density - $1.60 \mathrm{~g} / \mathrm{cm}^{3}$;

- density of solids $-2.70 \mathrm{~g} / \mathrm{cm}^{3}$;

- porosity index - 0.68 u.f.;

- water saturation coefficient - 0.76 u.f.;

- humidity at the limit of plasticity -0.21 u.f.;

- liquid limit - 0.34;

- plasticity index -0.13 u.f.;

- index of liquidity $<0$;

- deformation modulus in natural state - $21 \mathrm{MPa}$;

- deformation modulus at water saturation - $17 \mathrm{MPa}$;

- angle of internal friction $-23^{\circ}$;

- specific cohesion $-27 \mathrm{kPa}$. 
Below EGE-2 is the low-strength sandstone. Below the low-strength sandstone is the soft sandstone. Ground waters in the survey area up to a depth of $23.0 \mathrm{~m}$ are not opened by the wells.

\section{Statement of the problem and the decision}

When performing checking calculations of bases and foundations deformation of the object, the need to reduce the absolute value of the settlement has been revealed.

The settlement can be reduced by increasing the deformation modulus of the subsiding soil that is to reduce its compressibility. Moreover, the value of the required reduction of compressibility or increase of the value of the deformation modulus is determined by the calculation using the settlement permissible value of the designed building according to table G.1. Appendix G [1]. A design company requested us to project an artificially improved base under the monolithic foundation slab according to the following conditions: the exception of subsidence properties of EGE-1 to a depth of $5 \mathrm{~m}$ and the increase of the deformation modulus up to $20 \mathrm{MPa}$ in moistened condition.

After considering the possible options for engineering and geological conditions of the construction site described above, a variant of artificially improved soil of the base, with construction of rigid reinforcing elements in the form of piles in rolled wells filled with lean concrete, was adopted. Currently, LLC "NovTekhStroi" (Orenburg, Russia) together with LLC "OKB "NIS" (Orenburg, Russia) has developed, produced and implemented a number of universal mobile installations for the construction of rolled wells using rollers of different designs, each with its own field of application. E.g., we have installations on the basis of wheel loader excavators, on the basis of a swing excavator, on the basis of wheel tractors with "breaking frame", and also a portable installation for working in tight working space including basements. These installations have a number of advantages in comparison with drilling rigs based on vehicle chassis. First of all, this is a large torque on the working body, a large one-time stroke of the working body (up to $9 \mathrm{~m}$ ), fast and exact access to the location of the design well and increased cross-country capacity. A general view of the installation with the working body is shown in Fig.1.

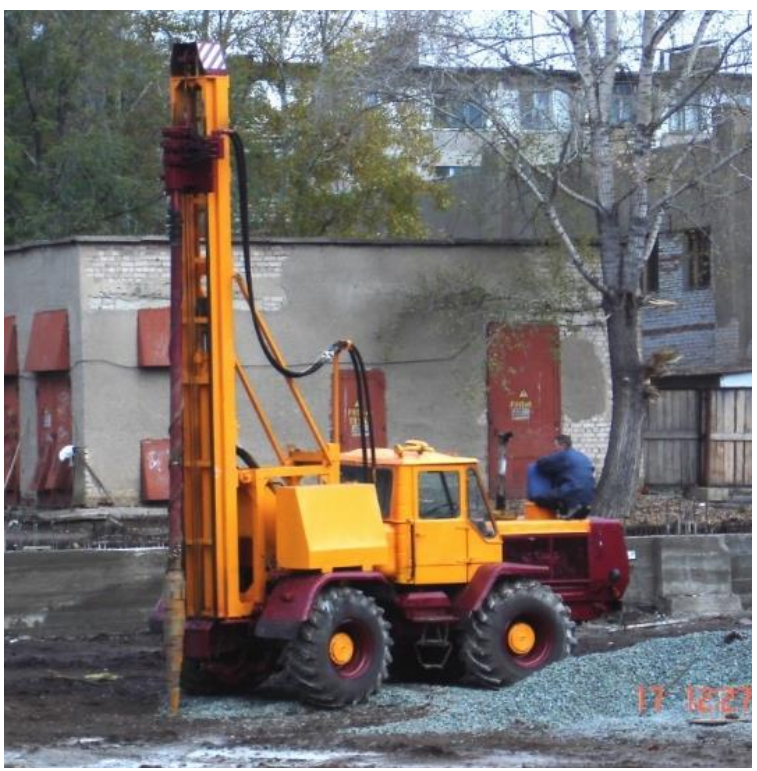

Fig. 1. The general view of the installation for the construction of rolled piles - NIS 55 . 
The presence of these installations and their high productivity (one installation produces up to 50 rolled wells with a depth of $5 \mathrm{~m}$ per shift) have led to the widespread introduction of the method of rolling out in construction of foundations in our region.

The technology of the construction of in situ piles in rolled wells has the following advantages:

- sufficiently high efficiency factor during the process of construction of the well;

- there is no need to clean the soil during the construction of the well, as the roller presses the soil into the walls of the well, significantly compacting them;

- there is no dynamic impact on adjacent buildings and structures.

As the subsidence soils are almost always in a solid state it is necessary to accelerate the process of construction of the rolled wells by constructing pilot holes of different diameters.

The peculiarity of the production technology of in situ piles in rolled wells is that the pile is made in wells and the soil in the wells is not extracted to the surface, as during the boring, but pressed into the surrounding massif.

That is, well rolling is a continuous process of formation of a conical-cylindrical cavity in the soil by compacting it into the walls of the well. The process is carried out by a special hinged tool, a roller of wells, the design of which can be of different types.

Due to this technology, physical and mechanical properties of the soil in the compacted area surrounding the well are significantly improved and subsiding properties in subsiding soils are eliminated. The experience of using of such piles is described in $[2,3]$.

\section{Design of the artificially improved base}

When rolling out a well in solid subsidence soils the roller and, especially, its tip are heated to $500^{\circ} \mathrm{C}$ or more. The material of the roller must have a high degree of resistance to abrasion and heating.

To reduce the degree of heating of the tip, the use of water is obligatory, since water:

- cools the tip and the edge of the roller;

- reduces the friction of the side surface of the roller on the soil;

- increases the ability of soils to form a stable wellbore of the rolled well of the required depth and diameter;

- creates optimal conditions for the formation of a compacted area of the borehole environment.

The idle time of the rolled wells in subsidence soils before concreting should be no more than three days.

After determining the characteristic values of compressibility (deformation modulus), the necessary distance between the rigid elements (piles in rolled wells) is calculated, taking into account the rigidness of the material filling the formed well, and the physical characteristics of the surrounding subsiding soil [4].

At the same time, it is obligatory to have the results of static penetration test on the site. These results allow:

- to clarify the nature and degree of variability of soil conditions of the site;

- to determine the reasons of discrepancy of the mode of rolling out with the designed one;

- to get preliminary data on the bearing capacity of piles in rolled wells.

For preliminary calculations it is recommended in [3] to determine the diameter of the compacted area, which can be obtained after rolling, by the formula:

$$
\mathrm{d}_{\mathrm{y}}=\gamma_{c} \cdot \sqrt{p d s /(p d s-p d)}
$$


where $\gamma c$ is the coefficient of soil working conditions, taken as $>1$, which is specified experimentally for specific soil conditions;

$\mathrm{d}$ is the diameter of the roller, $\mathrm{m}$;

pds is the density of dry compacted soil, $\mathrm{t} / \mathrm{m}^{3}$; accepted for subsiding soil equal to $1.65 \mathrm{t} / \mathrm{m}^{3}$; $\mathrm{pd}$ is the dry soil density in natural laying down, $\mathrm{t} / \mathrm{m}^{3}$.

However, due to the fact that in the reference [5] it is specified that in subsiding soils of the first type of subsidence, while rolling out wells, it is necessary to provide application of the compacted areas of neighboring wells for elimination of subsidence soil properties of inter-pile space and the area adjoining to the foundation. This explanation indicates the use of the soil behavior coefficient equal to 0.95 , according to the formula 166 [6].

The technology of construction of the rigid elements is as follows:

The wells for the in situ pile construction are estimated, according to the calculations, on the distance between the rows and in the row and are performed to a predetermined depth by a roller with a diameter of $250 \mathrm{~mm}$ and filled with lean concrete of class B 7.5. The placement of piles for the soil conditions of the described object is shown in Fig. 2.



Fig. 2. Fragment of pile placement plan in rolled wells.

The height of the filling with concrete is $30 \mathrm{~cm}$ below ground surface of the excavation bottom. These $30 \mathrm{~cm}$ of the well are filled with medium sand or coarse sand with a layer-bylayer compaction, 12 hours after concreting the pile (see Fig. 3). The use of compacted sand allows arranging a buffer layer between the foundation base and the body of the rigid element, which provides a redistribution of the load from the foundation base in the massif of compacted soil.

- after filling the well with the sand, the lay-out of the excavation bottom surface is carried out with soil trimming to the level of $5 \mathrm{~cm}$ above the bottom of the foundation mat;

- the true surface of the excavation bottom is further compacted by a vibrating roller, due to the fact that in the performing of wells with the use of a roller, the soil loosens to a depth of $30 \mathrm{~cm}-50 \mathrm{~cm}$. That is proved by the presence of the foundation uplift at the wellhead, which is explained by the formation of a compacted area with the displacement of the soil upwards. - when heating concrete in wells with the use of heating wires, after 4-6 days it is possible to perform plate load tests to determine the deformation modulus of the soil, improved by the method of reinforcement with rigid elements (in this case, concrete piles in rolled wells). 


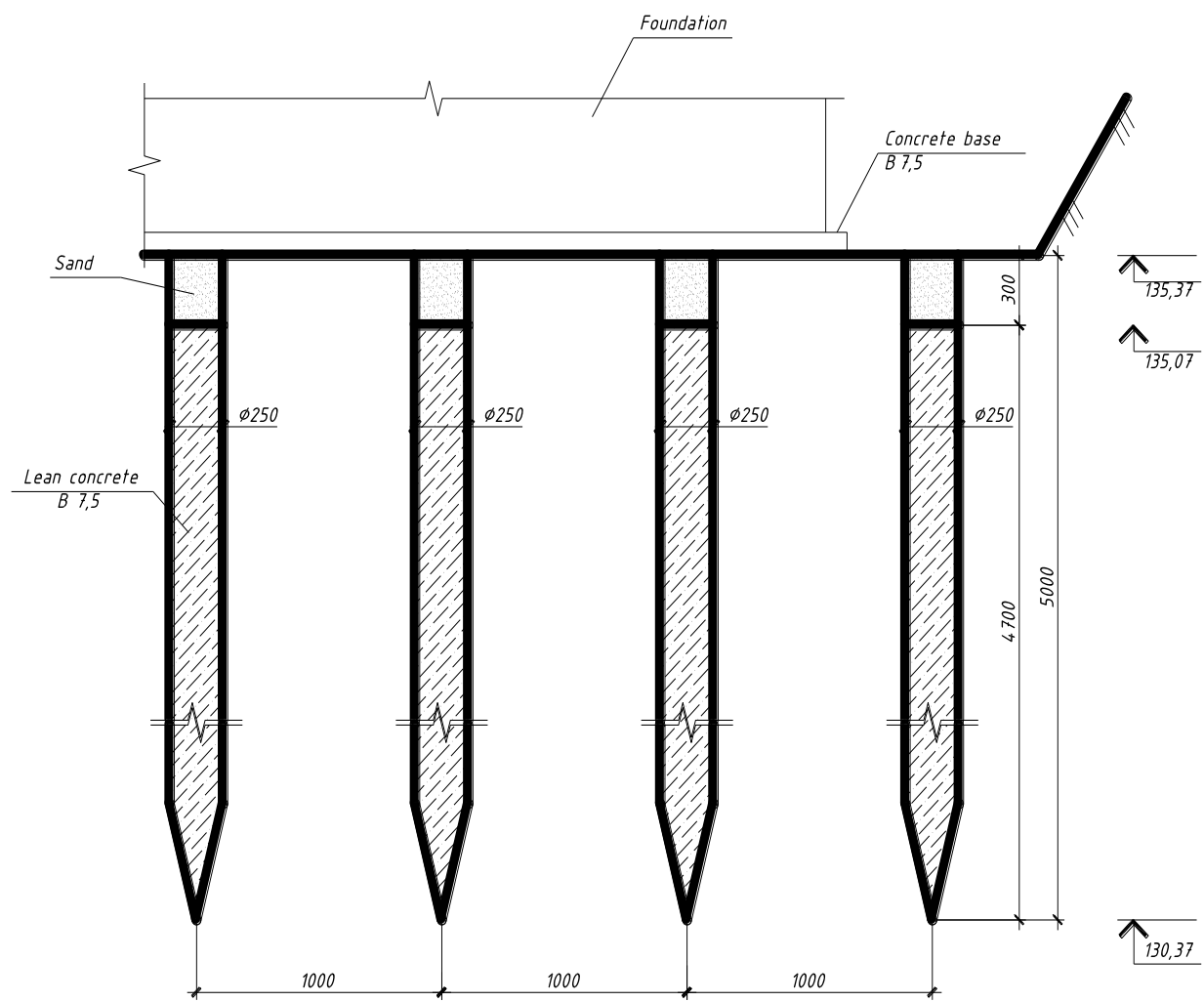

Fig. 3. $\log 1-1$.

The planned equivalent (reduced) deformation modulus, taking into account the step of piles and the filling material of the rolled-out wells, can be determined by the approximate formula given in [7]:

$$
E_{\ni}=\alpha\left(1-\alpha_{A}\right) E_{q}+\alpha_{A} \cdot E_{c},
$$

where $\alpha$ is an empirical coefficient depending on the type of the filler in the well; equal to 1.10 when rolling out the wells;

$\mathrm{E}_{\mathrm{q}}$ is a deformation modulus of the surrounding soil, $\mathrm{MPa}$, determined by the results of engineering-geological surveys;

$\mathrm{E}_{\mathrm{c}}$ is a deformation modulus of the material filling the well;

$\alpha_{\mathrm{A}}$ is the coefficient determined by the formula $\alpha_{A}=\frac{A_{c}}{A_{g r}}$, where

Ac is the area of filled well, $\mathrm{m}^{2}$;

$\mathrm{A}_{\mathrm{gr}}$ is the area of the soil around piles, taking into account a step of piles, $\mathrm{m}^{2}$.

Using the described formula (2) for the previously listed characteristics of subsiding soil and the filling of rolled wells that are located with a step of $1 \mathrm{~m}$ with lean concrete of class B 7.5, we get the planned equivalent deformation modulus equal to 27.0 MPa.

\section{Checking of the obtained results}

To determine the actual deformation modulus of artificially improved soil, after driving of the piles in rolled wells, plate load tests were performed around the area by a plate of 5000 
$\mathrm{cm}^{2}$, in accordance with GOST 20276-2012 "Soils. Field methods for determining the strength and strain characteristics". The peculiarity of the plate load tests is that after cleaning the test surface and constructing the sand cushion with a thickness of $1-3 \mathrm{~cm}$, the plate is installed in such a way that its centre coincides with the axis of the pile made in the rolled well. With such placement of the plate, the compressibility of the artificially improved base is influenced by the presence of rigid pile body, as well as by the compacted soil surrounding the pile. The plate load tests allowed determining the values of the deformation modulus, after the double test, equal to 22.8 $\mathrm{MPa}$ and 20.4 MPa. Thus, the designers' request was fulfilled. The differences in the values of the deformation moduluses, calculated by the approximate formula and obtained in the plate load test, may be explained by the different area of the soil in the determination of the coefficient $\alpha_{A}$. So, at the accepted step of piles of $100 \mathrm{~cm}$, it turns out, that under the plate with the area of $5000 \mathrm{~cm}^{2}$ and with the diameter of $79.8 \mathrm{~cm}$ the body of an in situ pile and the part of a compacted pile are situated. This point must be taken into account by adding to the formula (1) the correction coefficient which may be obtained during the gathering of calculation and field plate load test results.

\section{Conclusions}

1. The use of reinforcement of subsiding soil with rigid elements in the form of piles in rolled wells determined effectiveness of this variant.

2. To determine the deformation modulus of the artificially improved soil the formula (1) may be used.

3. Quality monitoring must be fulfilled by plate load tests according to Russian Standard GOST 20276-2012.

\section{References}

1. Russian Standard SP 22.13330.2016

2. O.P. Lomov, Collected papers of int. scientific and technical conf. Modern geotechnologies in construction and their scientific and technical support (St. Petersburg, 2014)

3. V.P. Perov, Collected papers of scientific and technical conf. Mechanic of soils in geotechnics and foundation engineering (Novocherkassk, 2012)

4. Russian State Standard SNiP 3.01.01.85

5. Recommendations for the design and installation of pile piles in rolled-out wells (Moscow, 2000)

6. Russian State Standard SNiP 2.02.01.83

7. Design and construction of bases and structures of reinforced soil. Manual to building regulations of the Republic of Belarus (2002) 